\title{
Variability and trends of heating degree-days in Argentina
}

\author{
M. Elizabeth Castañeda ${ }^{\mathrm{a}, \mathrm{b} *}$ and Federico Claus ${ }^{\mathrm{a}}$ \\ a Departamento de Ciencias de la Atmósfera y los Océanos - FCEN, University of Buenos Aires, Argentina \\ ${ }^{\mathrm{b}}$ Consejo Nacional de Investigaciones Cientificas CONICET, Argentina
}

\begin{abstract}
This study analyses heating degree-days (HDDs) in Argentina during the period 1900-2008. Gridded temperature data provided by the University of Delaware were analysed to calculate monthly and annual cumulative HDDs. Mean, maximum and minimum values as well as the average duration of the heating season are used to characterize the mean features of the region. Spatial variations are driven by latitude and altitude. The analysis of the temporal distribution of HDDs reveals that the centre of the mean heating season varies from mid-June to mid-July. The length of the cold season grows with increasing latitude and westward with increasing altitude. In the high Andes, the heating season extends all year round. S-mode principal component analysis is used to identify sub-groups of grid points with similar temporal variability. Negative trends in annual cumulative HDDs are detected in most of the country. Linear and nonlinear trends as well as temporal statistics are examined for inter- and intra-annual variability of HDDs to discuss its potential incidence on residential use of natural gas. Seasonal increases in natural gas consumption in the country, including the effect of regional price benefits, could be now better explained not only by population growth but also by the spatial and temporal characterization of the HDD season.
\end{abstract}

KEY WORDS heating degree-days; Argentina; principal component analysis; temporal statistics; trends; gas consumption

Received 3 June 2011; Revised 20 July 2012; Accepted 31 July 2012

\section{Introduction}

Argentina has a wide range of climates, from tropical to polar, through mid-latitude steppe and humid subtropical. As altitudes in the eastern part of Argentina, north of $40{ }^{\circ} \mathrm{S}$, hardly exceed $500 \mathrm{~m}$ above mean sea level, main factors affecting the temperature distribution are latitude and the ocean (Prohaska, 1976). In the south of $40^{\circ} \mathrm{S}$, temperature contours are relevant only in some coastal areas. In the west of Argentina, the presence of the impressive Andes Cordillera makes the outlining of temperature contours difficult. Studies of temperature variability or of any derived index will reflect such diversity. Therefore, to achieve correct results and reliable conclusions, a careful analysis is required.

Previous studies indicate that, in the past decades, warming in extratropical regions of the Southern Hemisphere, particularly in South America, was much less than that in the Northern Hemisphere. Analysing observations of surface temperature over Argentina, Nuñez et al. (2008) detected a net cooling (about $-0.04{ }^{\circ} \mathrm{C}$ per decade) in the period 1961-2000. The authors also noted a strong decrease in daytime temperature amplitude north of $40^{\circ} \mathrm{S}$ associated to a strong decrease in maximum temperature along with a weak warming trend in minimum temperature.

Some studies have been published recently on temperature extremes in Argentina. Rusticucci and Vargas (2001)

\footnotetext{
* Correspondence to: M. Elizabeth Castañeda, Departamento de Ciencias de la Atmósfera y los Océanos, Facultad de Ciencias Exactas y Naturales, Intendente Guiraldes 2160, Ciudad Universitaria, Pabellón II, Piso 2, Ciudad de Buenos Aires, Argentina.

E-mail: eliza@at.fcen.uba.ar
}

presented an analysis of the interannual variability of warm and cold spells in northern Argentina. The number of extreme waves per year shows low-frequency variability, and biennial variability - which is more important in intensity than persistence - occurs in summer rather than in winter. Trends in summer and winter means, standard deviations and extremes were examined by Rusticucci and Barrucand (2004), whose results show negative trends in the number of cold nights and warm days, and a growth in the number of warm nights and cold days in several places, mainly in summer.

The degree-day method is normally used to estimate energy consumption for heating and cooling in residential, commercial and industrial buildings, as well as greenhouses, farms and warehouses (ASHRAE, 1989; Kadioğlu et al., 2001; Matzarakis and Balafoutis, 2004; Yildiz and Sosaoglu, 2007). Basically, degree-days are defined as the difference between mean daily temperature and a given temperature threshold.

According to Al-Homoud (1998), the consumption of energy is more difficult to analyse for cooling than heating degree-days (HDDs). Under warm temperatures, the effect of air humidity on human comfort needs to be considered, as the body's main mechanism for temperature regulation is cooling by evaporation. Mean annual water vapour pressure decreases markedly from north to south, and regions are found in Argentina with very low relative humidity (Patagonia). Other regions receive much moisture throughout the year from the South Atlantic anticyclone, such as the northeast of Argentina. In the centre of the country, humidity content varies widely. In view of the complexity of establishing 
common criteria for the whole country, this study will only estimate HDDs.

About one third of the natural gas consumed in the world - and in Argentina - is used to generate energy in the residential, commercial and industrial sectors for different uses such as cooking, heating, vehicle fuel, production of paper, metal and glass, and generation of electric power. Electricity is becoming an alternative to natural gas. However, the great natural gas consumption market and the large availability of this resource in Argentina favour natural gas consumption even when gas is produced far from the major consumption centres. In Argentina, distances may be as large as $2000 \mathrm{~km}$.

The aim of this study is to analyse the temporal behaviour of the geographic distribution of HDDs, its trends and temporal statistics to discuss possible seasonal changes and consequently identify the regions that should address potential increases in natural gas demand.

\section{Data and methods}

A 'degree-day' is a measure of the departure of mean temperature from the temperature of human comfort, which according to many authors is $18.3^{\circ} \mathrm{C}\left(65^{\circ} \mathrm{F}\right)$ (Thom, 1954). Using comfort temperature as a threshold, HDD will be $18.3^{\circ} \mathrm{C}-T$, where $T$ is the mean temperature on a given day. In addition, cumulative degree-days are obtained as the sum of HDDs.

Terrestrial Air Temperature Gridded Monthly Time Series (Version 2.01) for the period 1900-2008 (http:// climate.geog.udel.edu/ climate/index.shtml) of the University of Delaware were used in this study. Mean monthly air temperatures from the Global Historical Climatology Network (GHCN2; Peterson and Vose, 1997) were interpolated to a grid $0.5 \times 0.5$ degrees lat/long using an interpolation algorithm based on the spherical version of Shepard's distance-weighting method (Matsuura and Willmott, 2010).

The method proposed by Erb et al. (1983) was used to calculate HDDs. Those authors developed a useful procedure to estimate monthly degree-days based on mean monthly temperature, $T_{\mathrm{A}, \mathrm{m}}$, which in this case is represented by the mean monthly temperature at the grid points. Standard deviations of mean monthly temperatures from the annual mean, $\sigma_{\mathrm{yr}}$, and of mean daily temperatures from the monthly mean, $\sigma_{\mathrm{m}}$, were calculated as:

$$
\mathrm{HDD}_{\mathrm{m}}=\sigma_{\mathrm{m}} D_{\mathrm{m}}^{1.5}\left[\frac{h}{2}+\frac{\ln \left(\mathrm{e}^{-\mathrm{a} h}+\mathrm{e}^{\mathrm{a} h}\right)}{2 a}\right]
$$

where $\bar{T}_{\mathrm{A}, \mathrm{yr}}$ is the yearly average temperature, $D_{\mathrm{m}}$ the number of days in a month,

$$
\begin{aligned}
\sigma_{\mathrm{yr}} & =\sqrt{\frac{1}{12} \sum_{1}^{12}\left(\bar{T}_{\mathrm{A}, \mathrm{m}}-\bar{T}_{\mathrm{A}, \mathrm{yr}}\right)^{2}} \\
\sigma_{\mathrm{m}} & =1.45-0.029 T_{\mathrm{A}, \mathrm{m}}+0.0664 \sigma_{\mathrm{yr}}
\end{aligned}
$$

$$
h=\frac{T_{\text {Thres }}-\bar{T}_{\mathrm{A}, \mathrm{m}}}{\sigma_{\mathrm{m}} \sqrt{D_{\mathrm{m}}}}
$$

where $T_{\text {Thres }}$ is the threshold temperature for calculating HDDs and $a=1.698 \sqrt{D_{\mathrm{m}}}$.

For a more explicit description of the method and the use of monthly means to calculate a daily statistic, refer to Erbs et al. (1983). Monthly totals of HDD were calculated using mean monthly temperatures with a threshold of $18.3^{\circ} \mathrm{C}$. Finally, cumulative annual HDDs were calculated as the sum of the monthly totals of the year.

The temporal behaviour of annual cumulative HDDs was studied using the principal component analysis (PCA). A complete description of the PCA and its applications on meteorological and climatological variables can be found in Barry and Perry (1973), Preisendorfer (1988) and more recently in Wilks (2005).

Two types of PCA are usually applied in meteorological and climatological studies to analyse variables in space or time. The S-mode involves the analysis of time series from different sites, the statistical variable under study being the time series of a meteorological or climatological variable that can be considered continuous in space and time. The S-mode aims at isolating similarly covarying grid points (Richman, 1986). The Tmode is used to analyse spatial fields in different times, which allows isolating subsets of fields with similar spatial structures. Although the S-mode makes it possible to identify regions with similar temporal variability, the T-mode can be used to classify spatial atmospheric fields.

The S-mode PCA was applied in this study to identify regions with similar temporal evolution of HDDs. The correlation coefficient was used instead of the covariance or other similarity coefficients given its advantages in PCA (see Jolliffe, 1986). Both the principal component scores (PCSs) or new variables - which are dimensionless time series (i.e. the main time patterns) - and the concomitant principal component loadings (PCLs) which are the fields of correlation between PCSs time series and the real time series at each of the grid points in the spatial domain - were considered in the PCA. According to Richman and Gong (1999), if a correlation matrix is used as the similarity coefficient, the smallest loading absolute value having physical meaning ranges from 0.2 to 0.35 , depending on the data set analysed. In our study, the threshold selected for significant loading values is shaded in grey in PCLs maps within \pm 0.3 contours. In other words, the gridded time series included in the shaded areas will behave as described by the $P C$ score and may be considered as a set of grid points having similar evolution in time.

Mean seasonal climate characteristics may occur over large regions at different times of the year. To study those characteristics, temporal statistics was calculated for annual cumulative HDDs, following the procedure proposed by Harrington and Cerveny (1988). This method allows analysing the temporal distribution of the variable 
by defining the following statistics: the first moment, or temporal mean, the average time of the HDD centre of gravity; the second moment, or temporal standard deviation, a measure of the annual spread of HDDs; and the third moment, or temporal skew, a measure of the symmetry of annual HDDs (for further computational information for these statistics, see Harrington and Cerveny, 1988).

Linear and nonlinear trends were calculated for annual cumulative HDDs to analyse changes in time from a linear variation perspective and also assuming alternate periods of warming and cooling in the region, as well as a possible subsequent switch in natural gas consumption.

\section{Results and discussion}

3.1. Mean behaviour of the geographic distribution of HDDs in Argentina

The features of the average distribution of HDDs over Argentina (Figure 1(a)), maximum values (Figure 1(b)), minimum values (Figure 1(c)) and mean duration of the heating season (Figure 1(d)) in the period under study are discussed. In general terms, variations are mainly forced by two drivers, latitude and elevation above mean sea level, as values grow towards the south and the west of the country. This coincides with the bio-environmental classification in Rule 11603 of IRAM (Argentine Institute of Normalization, 1996), which describes the bioclimatic characteristics of the country to establish building guidelines. In Patagonia, located at high latitudes, cumulative annual HDDs range from $1500^{\circ}$ to $2000^{\circ}$ (Figure 1(b) and (c)), with annual duration; this is also observed in the Andes. In the rest of the country, maximum values are below $500^{\circ}$, with a mean duration of 5 months, concentrated between May and September, with gradual changes, both in terms of increasing duration of the heating season and of annual cumulative HDDs.

The distribution of population in the country, the level of comfort for human settlement in different regions and the management of the natural gas network are all parameters to be taken into account when analysing energy demand. Climate-induced changes in demand for energy will affect energy supply models (Shea, 1997).

In Argentina, gas supply was in the hands of one state-owned company until 1992, when it was charged to nine companies distributed throughout the country (ENARGAS, 2008) (see Figure 2). In general, each of the companies has been assigned a group of provinces.

Information about the number of residential users per company and the natural gas delivered by each of the companies has been made publicly available only since 1993 (Figure 3). There is no obstacle to discussing the major aspects of consumption and population density, at least in the last 15 years of the period under study. The most densely populated area is the capital of the country and its southern suburbs (Region 1), most of the natural gas is delivered here. In the cooler and less densely populated south of the country (Region 9), the supply of gas has grown almost linearly since the beginning of 1990 s, from $53 \%$ of the gas supplied to Region 1 to more than $90 \%$ in 2008 , although population growth has been small. The second company in the country (Region 2), with about 30\% more inhabitants than the South, has received $85-90 \%$ less natural gas during the period. A similar situation is observed in the Pampas region (Region 5), where although population is greater by $45 \%$, gas supply is $25 \%$ lower on average. Another important fact is that population as well as the consumption of gas have grown in all regions, except the city of Buenos Aires, which only shows interannual variability of consumption, which can be explained by the use of other energy sources for heating, such as electricity. In the very humid North Eastern territory of Argentina (Region 4), natural gas consumption is lower than in the rest of the country, and therefore is not presented in this study.

We agree with ENARGAS (2008) that residential consumption of gas has grown in Argentina. ENARGAS notes that the daily per capita consumption is similar throughout the country. Residential and commercial consumption is directly related to temperature and is independent from the economic context and time (Gil, 2009). When temperature is above $18^{\circ} \mathrm{C}$, gas consumption is constant - used for cooking and water heating. With lower temperatures, users begin to heat their homes. Therefore, interannual variability of natural gas consumption can be said to be temperature-driven - i.e. it depends on the duration of the heating season and its possible variation in time and space. Long-term variability depends on population growth. We will now analyse the temporal behaviour of HDDs and its likely influence on the time and space variation in natural gas demand.

3.2. Temporal behaviour of the geographic distribution of HDDs in Argentina

The first three PCs explain $63.2 \%$ of the variance and represent clusters of three major subareas with different behaviour of temporal HDD anomalies. Results are presented in decreasing order of explained variance. Each figure includes PC loading maps (a) and the pattern of the concomitant time series PCSs (b).

The linear trend for PC time series is dimensionless, as well as the PC scores; therefore, PC scores may, at most, indicate the sign of the trend. Real trends were calculated using the decadal linear trend for the time series averaged over all the grid points within the significant area, i.e. the time series representative of each PC temporal score model within a given group (panel $b$, bold line). The significance of trends was analysed using the Student's $t$-test for mean differences (Wilks, 2005).

The first PC explains $38.5 \%$ of the variance and describes the behaviour of annual cumulative HDDs north of $45^{\circ} \mathrm{S}$ according to the map of the first PCLs (Figure 4(a)); HDD anomalies are well represented by the first model given that the significant loadings obtained range from 0.9 to 0.3 . Only a small region in the centre, 
(a)

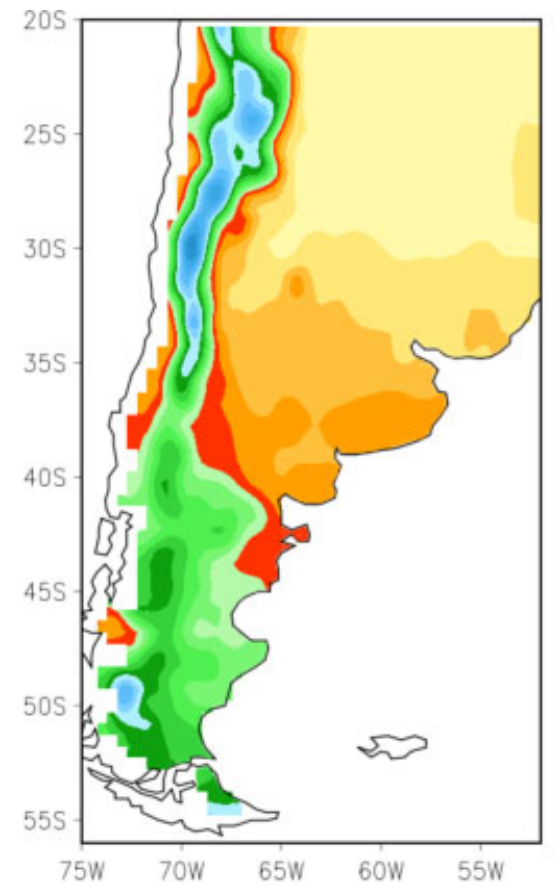

(c)

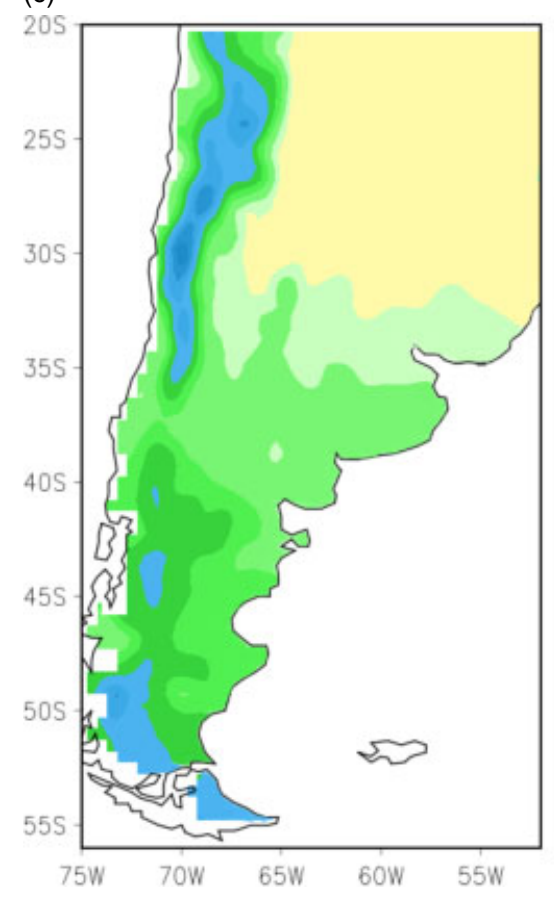

(b)
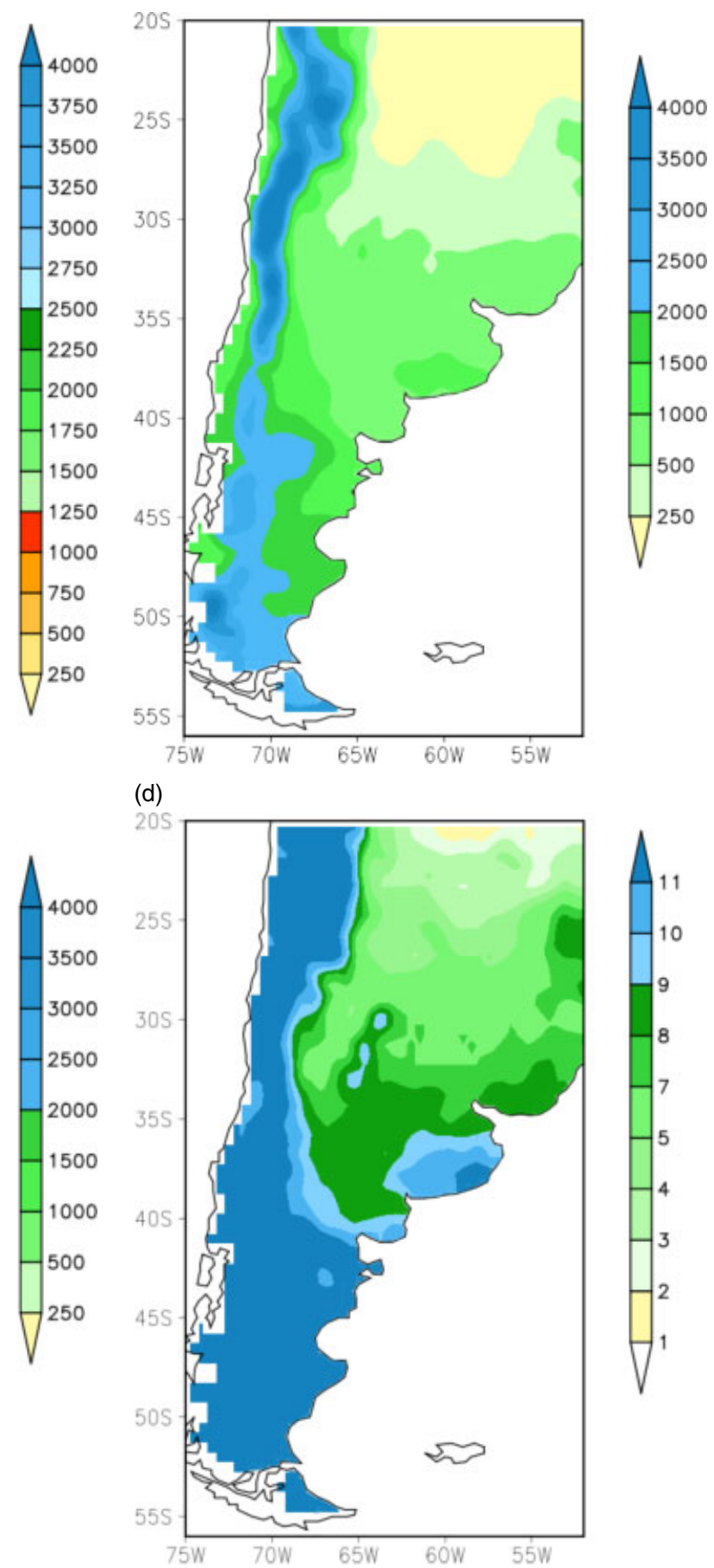

(d)

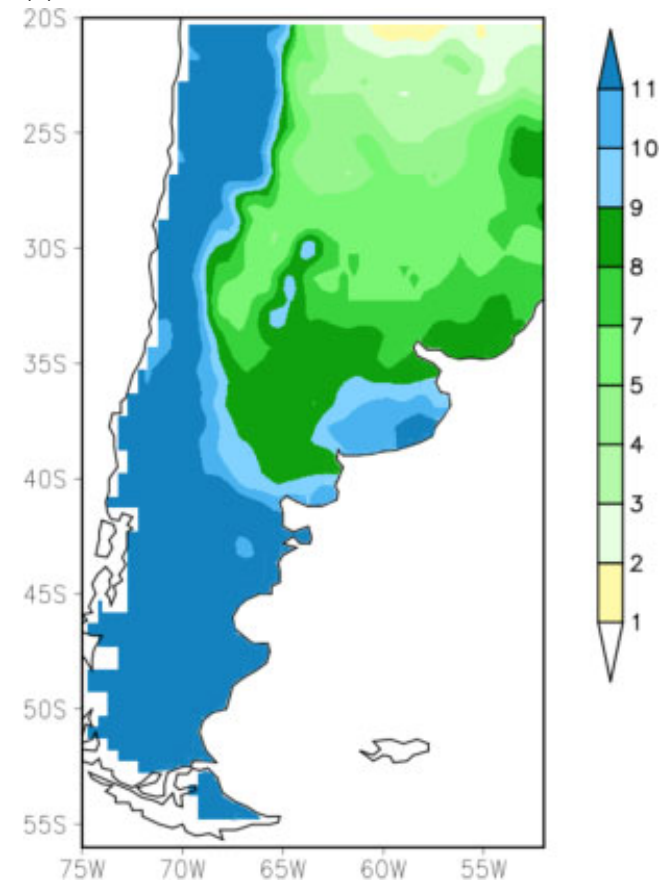

Figure 1. General features of heating degree-days (HDDs) over Argentina. (a) average distribution, (b) maximum values, (c) minimum values and (d) mean duration of the heat season.

around $33^{\circ} \mathrm{S} / 60^{\circ} \mathrm{W}$, seems to be the most important, with significant loadings $>0.9$. A marked rise in mean temperature has been observed in this region (Rusticucci and Penalba, 2000), clearly represented by the positive trends in seasonal maximum and minimum temperatures (Rusticucci and Barrucand, 2004). The PC loading pattern reveals a major negative trend of $-53.9^{\circ} \mathrm{HDD}$ per decade (see Figure 4(b)) estimated over the average time series. The trend is significant at $95 \%$ level, according to the Student's $t$-test. Negative trends of HDD accompany the rise in minimum temperature throughout the country, the decrease in maximum temperatures in the central region and the increase in Patagonia as observed by other researchers (e.g. Rusticucci and Barrucand, 2004).

The second temporal PC pattern (Figure 5(b)) explains $17.6 \%$ of the variance and describes the behaviour of cumulative annual HDD mainly south of $38^{\circ} \mathrm{S}$, according to the second map of PCLs (Figure 5(a)). A second signal, weak and with opposite sign, can also be observed in the north of the region. The mean negative trend 


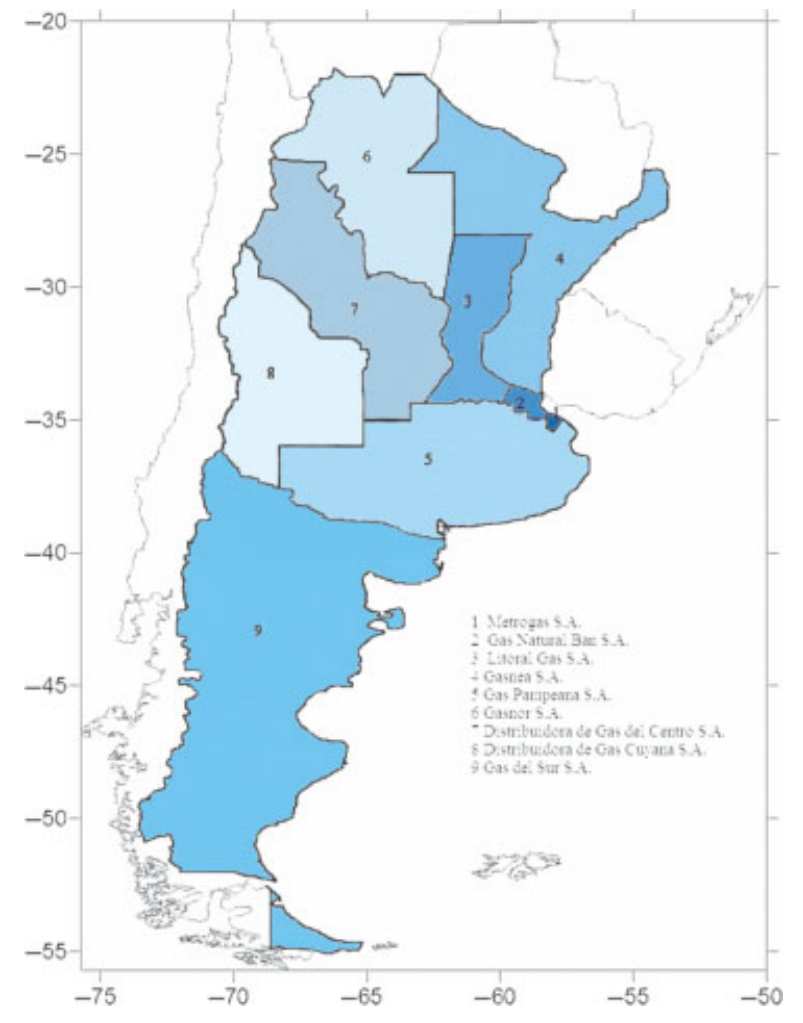

Figure 2. Natural gas suppliers in Argentina (Source: ENARGAS, 2008, www.enargas.com.ar).

calculated using the time series at the grid points belonging to the significant region is $-54.4^{\circ} \mathrm{HDD}$ per decade (Figure 5(b)), also significant at 95\% level. Gil (2009) pointed that the consumption of natural gas per user in southern Argentina is about double the consumption in the rest of the country with the same outdoor temperature. According to this author, the difference in prices might explain such consumption pattern, at least partially. The price of natural gas in the south is practically half the price in the rest of the country and further reduced by government subsidies.

The temporal pattern of the third PC (Figure 6(a) and (b)), explained by $7.1 \%$ of the variance, corresponds to HDD values at about $38^{\circ} \mathrm{S} / 70^{\circ} \mathrm{W}$, in the centre of the Province of Neuquen. A smooth non-significant negative trend of $-15^{\circ} \mathrm{HDD}$ per decade (see Figure 6(b)) was estimated over the average time series. Positive temperature trends were identified by Masiokas et al. (2008) from 1912 to 2002, related to the occurrence of significant changes in the glaciers of northeastern Patagonia during the past century.

\subsection{Temporal statistics}

The first temporal moment is the average time in which each grid point accumulates $50 \%$ of the annual cumulative HDD. In Argentina, this usually occurs between midJune (6.5) and mid-July (7.5) (Figure 7). The Provinces of Buenos Aires and the Patagonian region experience the average time between the second half of July and August, which are winter months. A 'mild' winter may cause natural gas consumption to drop, with consequent decrease in gas injection and transport. According to ENARGAS (2008), during the winter, gas carrying capacity is about $90 \%$. This level has remained relatively constant since the early 1990s (no previous statistical data available), but,

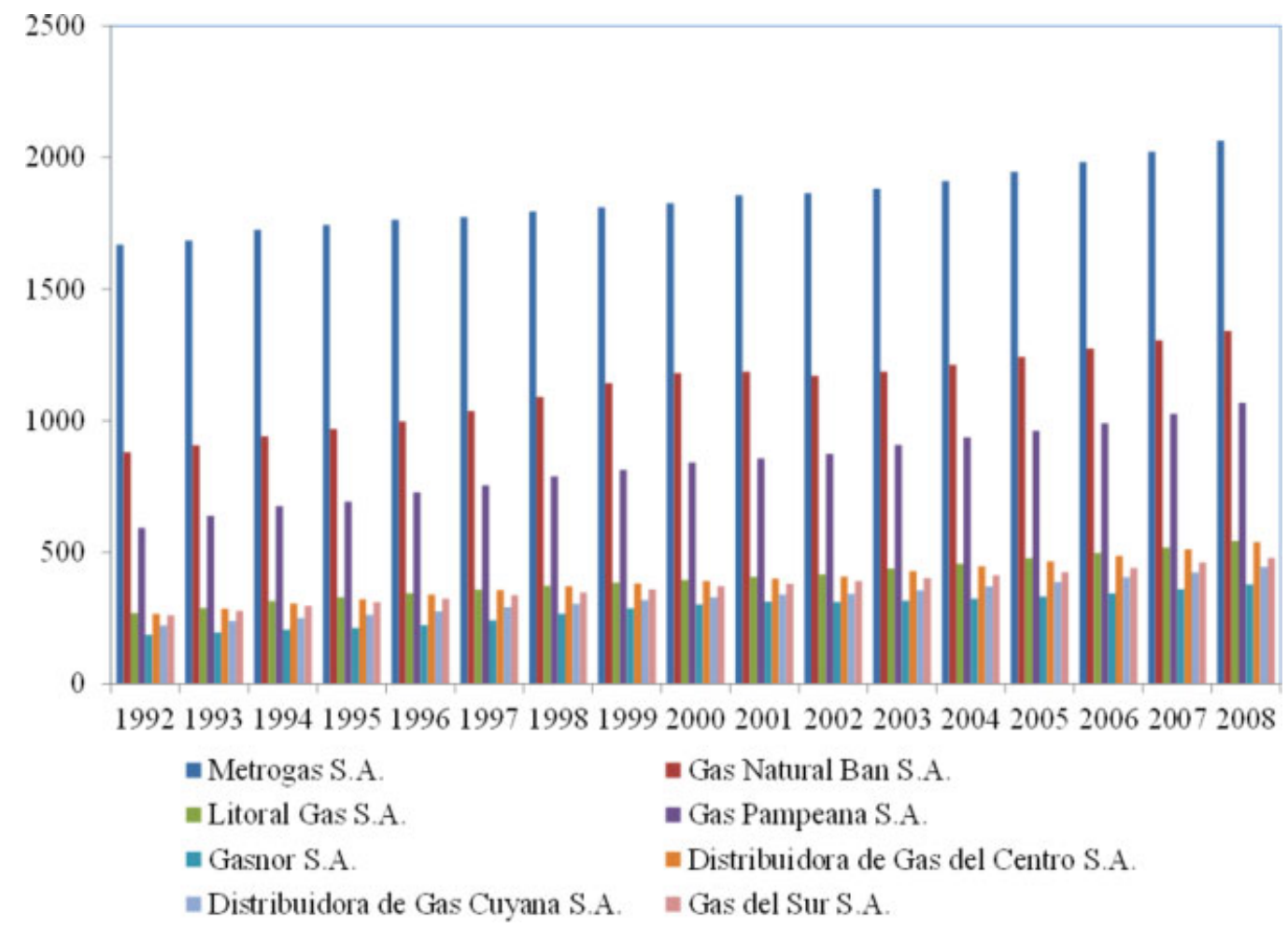

Figure 3. Number of residential users (in thousands) per company in the period 1992-2008. (Source: ENARGAS, 2008, www.enargas.com.ar). 
(a)

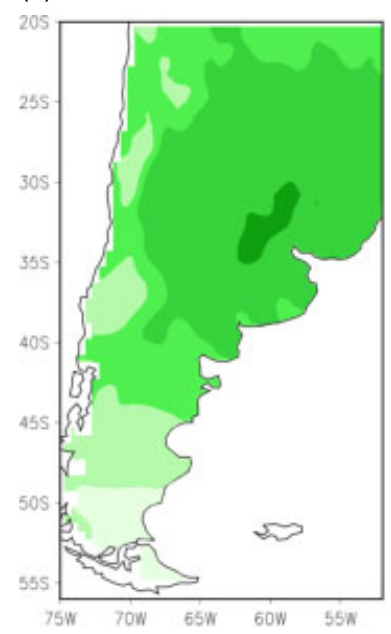

(b)

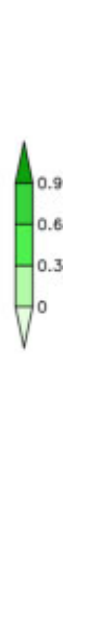

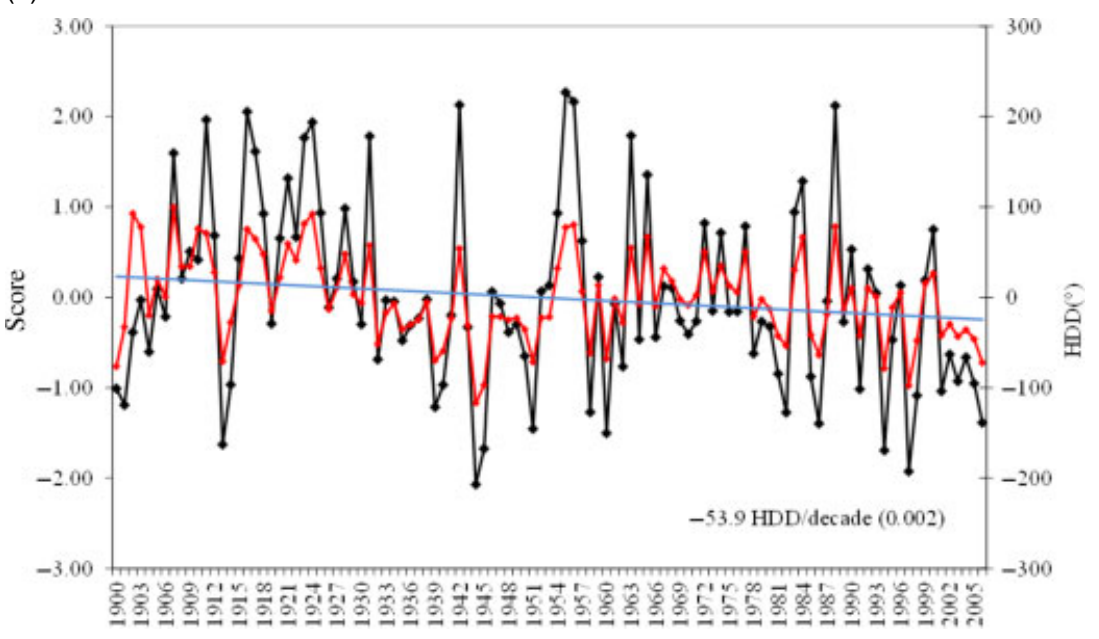

Figure 4. First PC: (a) PC loading map, contours at 0.3 intervals; (b) score pattern time series; average time series in long dashed line and linear trends in bold, trends values in HDD per decade and $p$-value in parentheses.

(a)

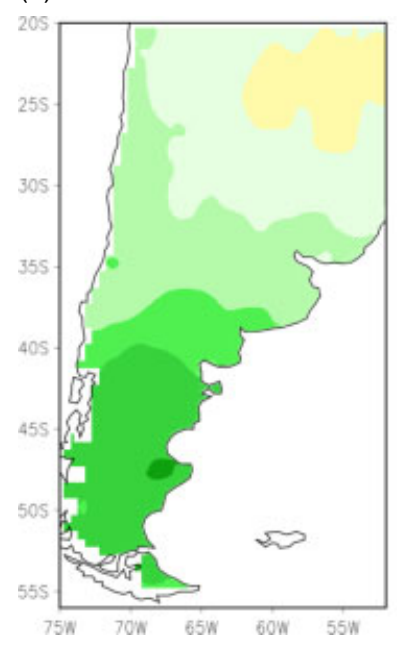

(b)

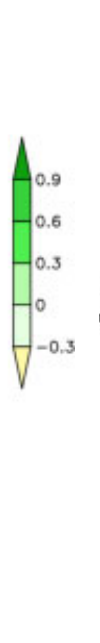

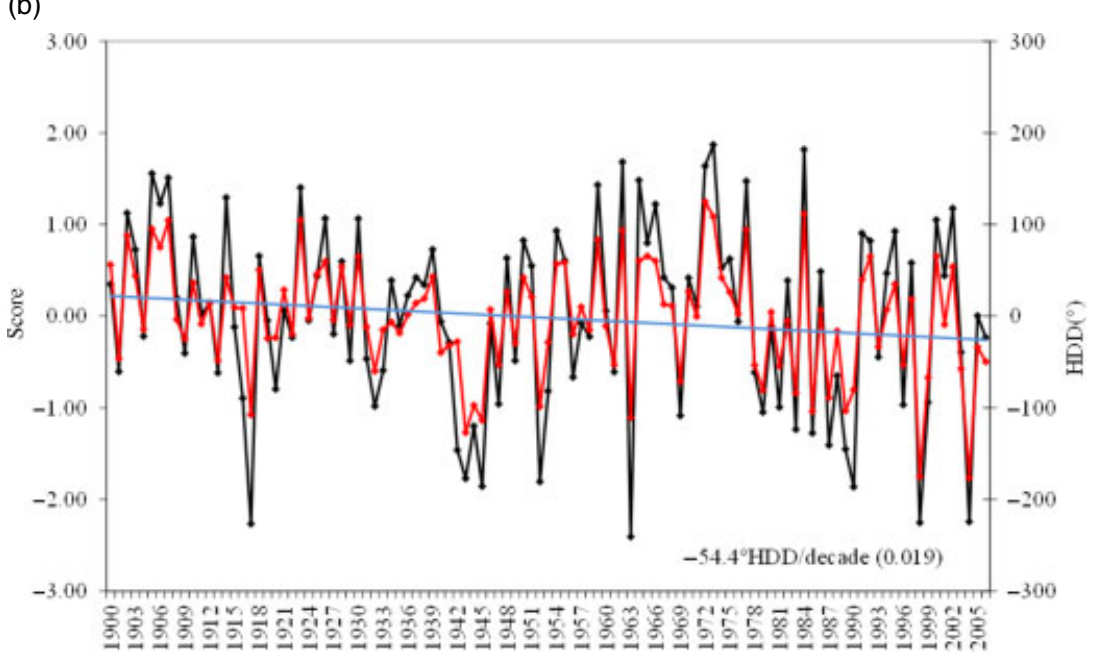

Figure 5. Second PC: (a) PC loading map, contours at 0.3 intervals; (b) score pattern time series; average time series in long dashed line and linear trends in bold, trends values in HDD per decade and $p$-value in parentheses.

(a)

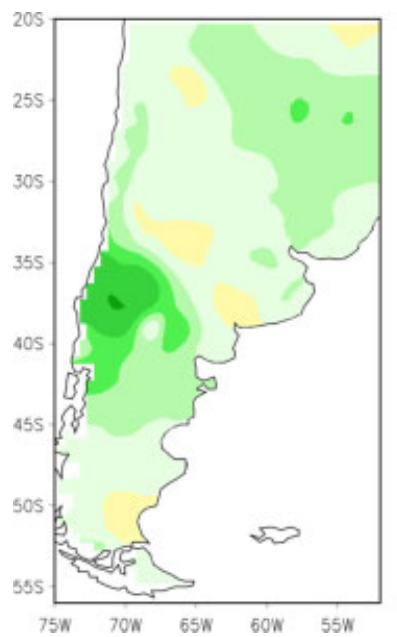

(b)

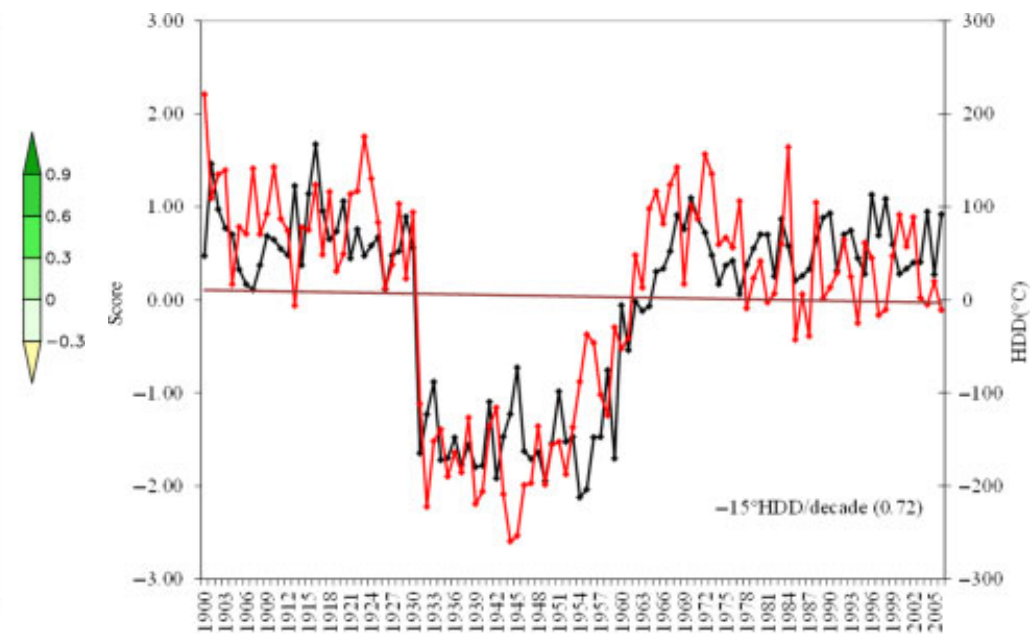

Figure 6. Third PC: (a) PC loading map, contours at 0.3 intervals; (b) score pattern time series; average time series (long dashed line) and linear trends (bold), trends values in HDD per decade and $p$-value in parentheses. 


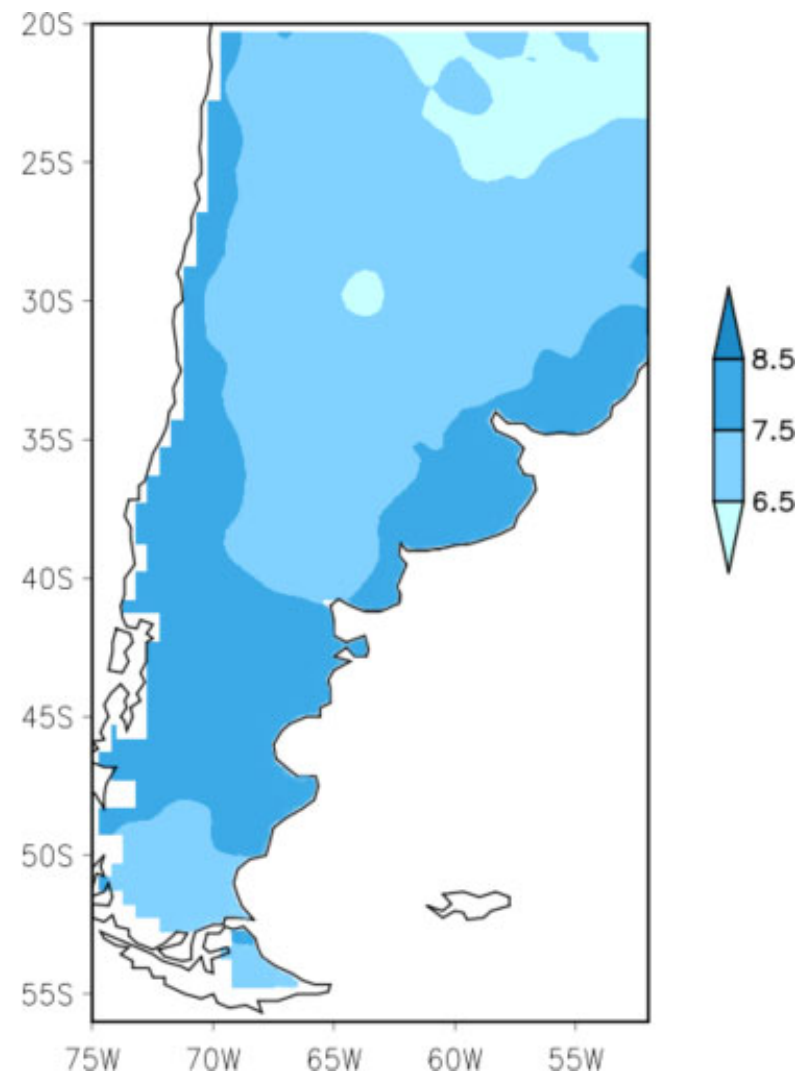

Figure 7. The temporal mean of the annual accumulated HDD.

given the climatic characteristics, the South is expected to have a longer heating season than lower latitudes.

Having assumed that annual cumulative HDDs have bell-shaped distribution, 1.96 times the standard deviation means that $95 \%$ of HDD events are distributed around the centre of gravity, i.e. the average month. Spatial patterns of temporal standard deviation show that values increase in the NE-SW direction (Figure 8). In highlatitude and -altitude regions, HDD seasons are long as can be expected, but HDD seasons are also long in the Province of Buenos Aires, where a standard deviation value of 3.5 may be interpreted as having a HDD season occurring within a 7 month period beginning in the first week of April and extending into October, the spring season. On the other hand, in Patagonia, the HDD season extends within 8 months, from the second week of March to the second week of November. In terms of the demand for natural gas, this suggests that although consumption peaks between July and August, the period of high consumption could be longer under favouring conditions, i.e. greater consumption might be related to longer heating seasons. The natural gas suppliers in the Andes region have no records of such an increase, probably because the population density is smaller; habitability is limited to low areas and, in some areas, other energy sources are used for heating, such as wood.

Skewness, the third moment, is a measure of dispersion and characterizes the symmetry of a distribution (zero for a symmetric distribution). Positive values indicate that most of the data in the distribution have placed early

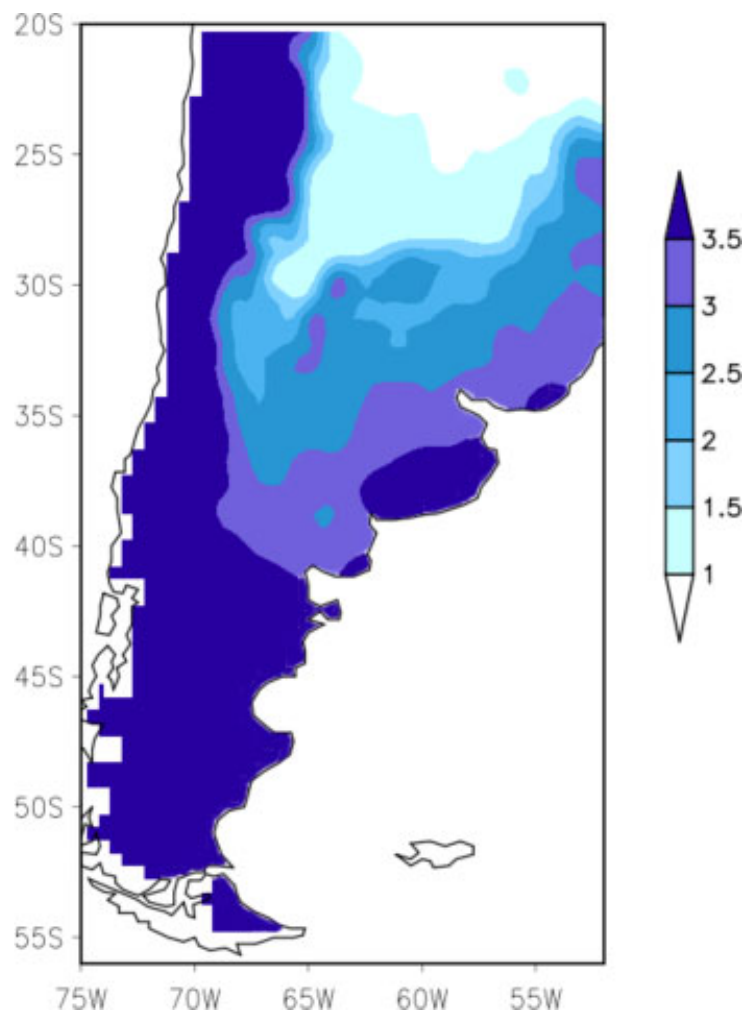

Figure 8 . The temporal standard deviation of the annual accumulated HDD.

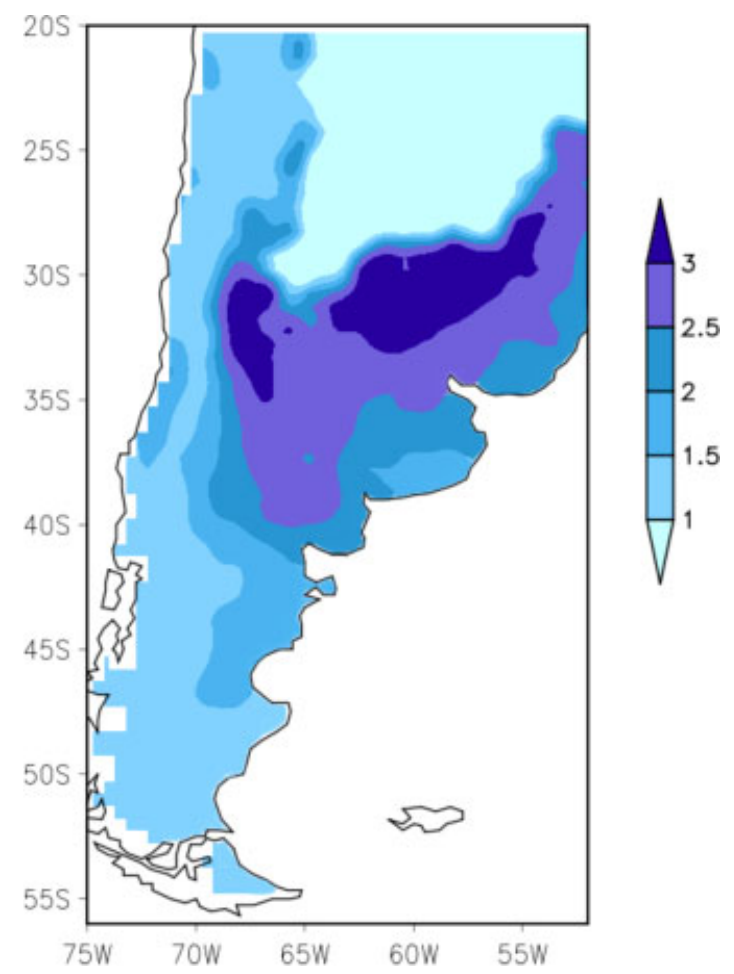

Figure 9. Temporal skewness of annual accumulated HDD.

in time, i.e. the majority of the data values are smaller than the mean. Areas with values around 2 or 3 (see Figure 9) are subject to frequent early HDD seasons, which is observed in more than half of the country: 
Annual HDDs accumulates early in the winter, late in the autumn seasons, when much gas is demanded for heating. In the south of the country and at high altitudes, values are between 1 and 2, more symmetric, which confirms that the heating season lasts practically all year round.

\subsection{Linear trends in HDDs}

Linear trend fit of HDD is directly related with temperature trend fits. In Argentina, trends in the mean, standard deviations and extremes were evaluated for summers (December-February, DEF) and winters (June-August, JJA) from 1959 to 1998 (Rusticucci and Barrucand 2004). Vincent et al. (2005) examined trends in indices of extreme daily temperatures in 1960-2000. These studies need to be taken into consideration as the mean temperature derives from maximum and minimum temperatures. Recently, Collins et al. (2009) demonstrated that temperature patterns in South America changed between 1948 and 2007.

As to long-term variability, linear trends of cumulative annual HDDs are negative in most of the country (Figure 10); shaded areas indicate trends significant at the $95 \%$ level, according to Student's $t$-test for mean differences, calculated at each grid point. Positive trends are observed in the north of Argentina, at around $40^{\circ} \mathrm{S}$

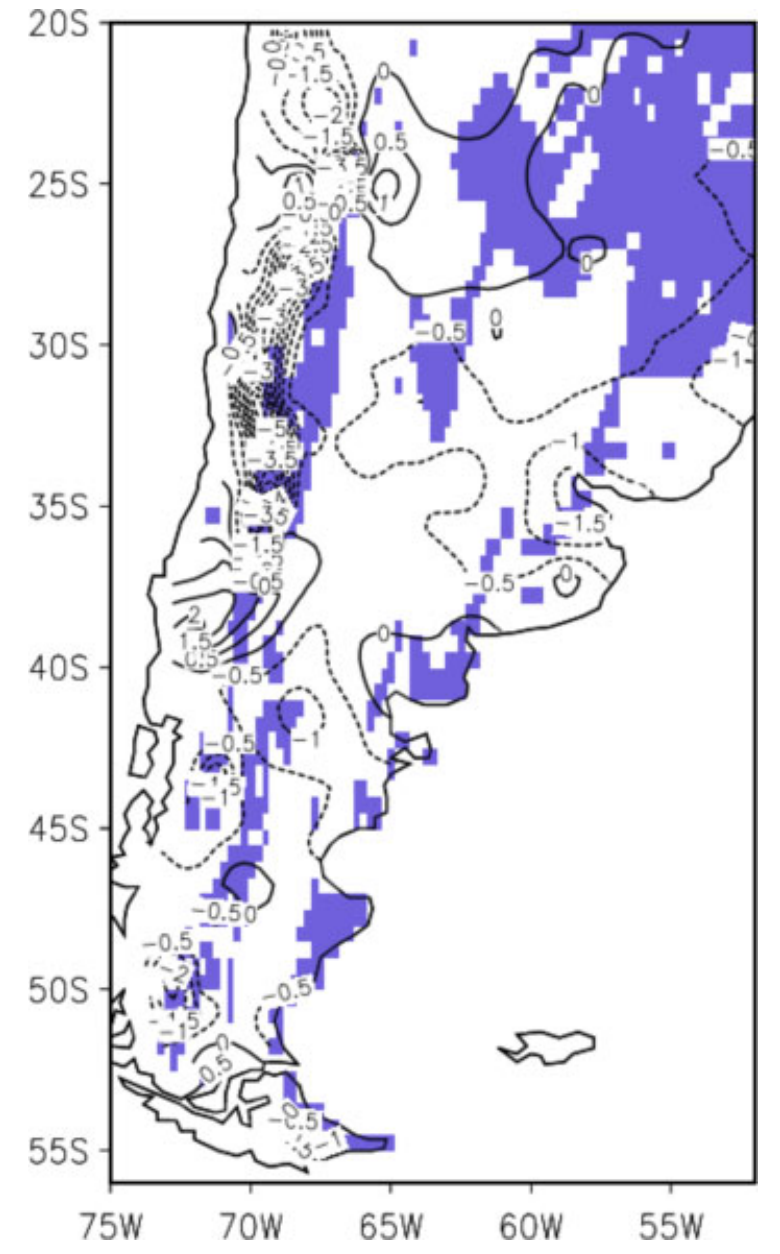

Figure 10. Linear fit of annual accumulated HDD for the period 1900-2008. Shaded areas are significant at the 95\% confidence level. along the coast and in the northeast of Patagonia. Rusticucci and Barrucand (2004) detected opposite trends for maximum and minimum temperatures for the first two regions. In the surroundings of the City of Buenos Aires, where many people have settled, strong negative trends are detected. All these results are compatible with those represented by the real time series synthesized by the PC Scores in Figures 4(a), 5(a) and 6(a).

\subsection{Nonlinear trends}

The previous section has briefly examined trends in HDDs, assuming progressive linear growth. To study the abrupt changes, nonlinear trends were calculated using the method described in Tomé and Miranda (2005), which uses consecutive linear segments to fit the data, where the number of breakpoints between segments and the slopes of the different segments are optimized simultaneously. The least square fit makes it possible to identify significant changes in trends in the time series objectively. This methodology is very time-consuming, because of the large number of grid points involved. Once breakpoints are found, it is crucial to establish a physical relation with the events reported. Tomé and Miranda (2005) discussed the statistical significance and robustness of the method by analysing a large number of simulations using synthetic series. The method was able to capture all partial trend values and the authors considered the usefulness of the method proven.

Limiting the number of breakpoints to one means that a cooling period might be assumed to be followed by a warming period, or vice versa. Figure 11 shows the distribution of breakpoint years in Argentina, for the best fit obtained for cumulative annual HDDs where only two segments were considered and only one trend sign change.

North of $35^{\circ} \mathrm{S}$, the region experiences changes early in time (1900-1920); towards higher latitudes, changes occur closer to the end of the century. The spatial coherence of the distribution of the breaking points, with neighbouring grid points experiencing similar changes in annual HDDs, also suggests that several regions have similar breakpoints. As mentioned before, results for the Andes region need to be discussed carefully.

Breakpoints in coastal areas are more recent; in the 1980 s, a noticeable change was recorded at $38^{\circ} \mathrm{S}$ approximately, where major urban centres have developed. Mar del Plata, a city located on the coast of the Atlantic Ocean, is one of the most important fishing ports, the greatest seaside resort and the seventh biggest city in Argentina. In the first half of the century, population grew more than $70 \%$ (INDEC, 2001), which implies a greater demand for natural gas. To the south, a breakpoint is observed around the 1960s in another major coastal area where population has grown significantly since the beginning of the century. This area also shows significant positive linear trends for annual cumulative HDDs, as described in the previous section. In fact, there has been a change in partial trends, with a decrease followed by an increase since 


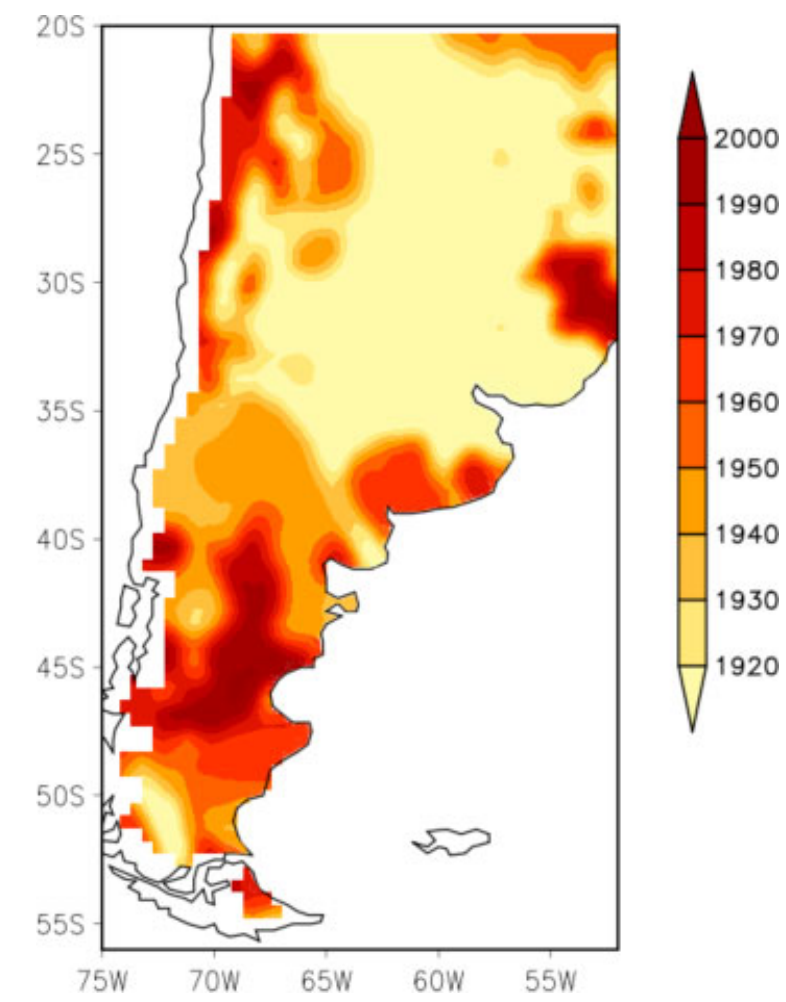

Figure 11. Breakpoint years obtained using Tomé and Miranda's (2005) method considering only two consecutive line segments.

the beginning of the 1960s. This means that a growth in population has been detected in middle latitudes with temperatures justifying high-energy demand, and a consistent record of changes in partial trends. This was also observed in studies of temperature extremes (Rusticucci and Barrucand, 2004).

The greatest heterogeneity in trend change dates is observed in Patagonia; diversity in breakpoint dates points to changes in trend during the second half of the century. The settlement process in Patagonia has been long. The region experienced explosive growth between 1947 and 1980, followed by a decline as from the 1990s (INDEC, 2001). The most populated area is the north of Patagonia, and the number of inhabitants decreases southward. A characteristic feature in the region is that people settle in urban centres, so only $10 \%$ of the population in the region is rural with a density of $1.5 \mathrm{hab} \mathrm{km}^{-2}$. The information available since 1993 shows moderate growth in the number of home users and high natural gas consumption, which relevant organizations rather ascribe to lower taxes than to changes in temperature. Therefore, we note that changes in trends and in the number of inhabitants in this region have occurred in the second half of the century, with no direct relation between them.

\section{Conclusions}

HDDs are a tool for estimating natural gas consumption for heating in residential and commercial buildings, as well as to discuss population redistribution within a country. When people move to another region, they face new climatic conditions and consequently change consumption habits, which may imply an increase in residential and commercial gas consumption (e.g. people moving to cooler areas need to get used to the new temperatures).

The variability of the main mean characteristics of annual cumulative HDDs indicates a north-south gradient driven by latitude and altitude. The heating season takes place from mid-June to mid-July, which corresponds to mid-winter, the temporal centre of the heating season. Cold seasons are longer with increasing latitude and to the west, with increasing altitude in the Andes, with sudden onset of the heating season ending fall. Heating seasons are longer, due to delayed beginning of summer.

Variations of HHDs have not been homogeneous in space or time in Argentina. In general, negative trends have been observed, coherent with changes in temperature observed by other researchers. The ocean influence becomes evident in areas where population has grown recently. On the other hand, changes have been detected in the partial trends of HDDs in several regions. Those changes have made it possible indirectly to point at possible changes in energy consumption habits, as long as changes in trend denote changes in temperature regimes. Information on the distribution of natural gas and the number of residential users reveals that residential consumption of natural gas has grown, with distinct regional differences. Those changes have been discussed by governmental bodies in terms of temperature variation, population distribution and tax exemptions. This study shows that natural gas consumption undergoes intra-annual variability, which is related with temperature, the average duration of the heating period, changes in duration throughout the year, the seasons that favour consumption in each region and long-term variability, where temporal trends combine with progressively increasing residential use of natural gas due to population growth.

\section{Acknowledgements}

The authors wish to thank the two anonymous reviewers for their very useful comments that improved this study and to Paula Richter for her valuable suggestions during the writing of this study. This work was partially supported by the University of Buenos Aires Grant UBA X092.

\section{References}

Al-Homoud MS. 1998. Variable-base heating and cooling degree-day data for 24 Saudi Arabian cities. ASHRAE Transactions 104(2): 320-330.

Argentine Institute of Normalization. 1996. IRAM 11603, Acondicionamiento térmico de edificios. Clasificación bioambiental de la República Argentina. Argentine Institute of Normalization: Argentina.

ASHRAE. 1989. Handbook of Fundamentals. ASHRAE, Inc.: Atlanta, GA, 28.1-28.9.

Barry RG, Perry AH. 1973. Synoptic Climatology: Methods and Applications. Taylor \& Francis: London, 555 pp. 
Collins JM, Rodrigues Chaves R, Da Silva Marques V. 2009. Temperature Variability Over South America. Journal of Climate 22: 5854-5869.

ENARGAS. 2008. Annual Newsletters. Ente Nacional Regulador del Gas. (Gas Control National Entity). Ministerio de Planificación Federal, Inversión Pública y Servicios: Argentina.

Erbs D, Klein SA, Bechman WA. 1983. Estimation of degree-days and ambient temperature bin data from monthly-average temperatures. ASHARE Journal 25: 60-65.

Gil S. 2009. Posibilidades de ahorro de gas en Argentina-Hacia un uso más eficiente de la energía. Pretrotécnia (Revista del Instituto Argentino del Petróleo y del Gas) L, N02, ISSN 0031-6598, 80-84.

Harrington JA, Cerveny RS. 1988. Application of temporal statistics in snow climatological studies. Physical Geography 9: 337-353.

INDEC. 2001. Instituto Nacional de Estadísticas y Censos (National Institute of Statistics and Censuses).

Jolliffe IT. 1986. Principal Component Analysis. Springer-Verlag: New York, $486 \mathrm{pp}$.

Kadioğlu M, Şen Z, Gültekin L. 2001. Variations and trends in turkish seasonal heating and cooling degree-days. Climatic Change 49 209-223.

Masiokas MH, Villalba R, Luckman BH, Lascano ME, Delgado S, Stepanek R. 2008. 20 $0^{t h}$-century glacier recession and regional hydroclimatic changes in northwestern Patagonia. Global and Planetary Change 60: 85-100.

Matsuura K, Willmott CJ. 2010. Terrestrial air temperature: 1900-2008 gridded monthly time series (version 2.01). Available at http:// climate.geog.udel.edu/;climate/html_pages/Global2_Ts_2009/ README.global_p_ts_2009.html

Matzarakis A, Balafoutis C. 2004. Heating degree-days over Greece as an index of energy consumption. International Journal of Climatology 24: 1817-1828.

Nuñez MN, Ciapessoni HH, Rolla A, Kalnay E, Cai M. 2008. Impact of land use and precipitation changes on surface temperature trends in Argentina. Journal of Geophysical Research 113: D06111, DOI: 10.1029/2007JD008638.

Peterson TC,Vose VS. 1997. An overview of the Global Historical Climatology Network temperature database. Bulletin of the American Meteorological Society 78: 2837-2849.
Preisendorfer RW. 1988. Principal Component Analysis in Meteorology and Oceanography. Elsevier: Amsterdam, The Netherlands, 436 pp.

Prohaska F. 1976. The climate of Argentina, Paraguay and Uruguay. In Climates of Central and South America. World Survey of Climatology, Vol. 12, Schwerdtfeger W (ed). Elsevier: Amsterdam, 13-112.

Richman MB. 1986. Rotation of principal components. Journal of Climatology 6: 293-335.

Richman MB, Gong X. 1999. Relationships between the definitions of the hyperplane width to the fidelity of principal component loading patterns. Journal of Climate 12: 1557-1576.

Rusticucci M, Barrucand M. 2004. Observed trends and changes in temperature extremes over Argentina. Journal of Climate 17: 4099-4107.

Rusticucci M, Penalba O. 2000. Interdecadal changes in the precipitation seasonal cycle over Southern South America and their relationship with surface temperature. Climate Research 16: 1-15.

Rusticucci M, Vargas W. 2001. Interannual variability of temperature spells over Argentina. Atmósfera 14: 75-86.

Shea J. 1997. The energy sector. In Applied Climatology: Principles and Practice, Thompson RD, Perry A (eds). Routledge: 352 pp.

Thom HCS. 1954. The rational relationship between heating degree days and temperature. Monthly Weather Review 82: 1-6.

Tomé AR, Miranda PMA. 2005. Continuous partial trends and lowfrequency oscillations of time series. Nonlinear Processes in Geophysics 12: 451-460.

Vincent LA, Peterson TC, Barros VR, Marino MB, Rusticucci M, Carrasco G, Ramirez E, Alves LM, Ambrizzi T, Berlato MA, Grimm AM, Marengo JA, Molion L, Moncunill DF, Rebello E, Anunciação YMT, Quintana J, Santos JL, Baez J, Coronel PG, Garcia J, Trebejos I, Bidegain M, Haylock MR, Karoly D. 2005. Observed trends in indices of daily temperature extremes in South America 1960-2000. Journal of Climate 18: 5011-5023.

Wilks D. 2005. Statistical Methods in the Atmospheric Sciences, Vol. 100,2 nd edn. (International Geophysics). Academic Press: London, UK, 627 pp.

Yildiz I, Sosaoglu B. 2007. Spatial distributions of heating, cooling, and industrial degree-days in Turkey. Theoretical and Applied Climatology 90: 249-261, DOI: 10.1007/s00704-006-0281-1. 